\title{
Adjustment for blood pressure when measuring pulse wave velocity in newly diagnosed untreated hypertensive patients
}

\author{
Strandhave $\mathrm{C}^{1}$, Svensson $\mathrm{M}^{2}$, Holdensen $\mathrm{K}^{1}$, Skov $\mathrm{CM}^{1}$, Krarup $\mathrm{H}^{3}$, Christensen $\mathrm{JH}^{1}$ \\ 'Department of Nephrology, Aalborg Hospital, Aarhus University Hospital \\ 2Department of Nephrology, Skejby Hospital, Aarhus University Hospital \\ ${ }^{3}$ Department of Clinical Biochemistry, Aalborg Hospital, Aarhus University Hospital
}

\section{Aim}

To investigate if mean arterial pressure (MAP) was superiorly correlated to pulse wave velocity (PWV) compared to systolic blood pressure (sysBP) in newly diagnosed untreated hypertension.

\section{Background}

PWV:

- A valid and well-documented predictor of cardiovascular risk in hypertensive patients

- Age and blood pressure (BP) modulate the level of PWV

- Essential to adjust for these potential confounders

- SysBP has been widely used for adjustment Laurent Set al. Aortic stiffness is an indepent
patients Hypertension 2001; 37: 1236 -1241

- In recent years, MAP has been favoured Determinants of pulse wave velocity in healthy people and in the presence of cardiovascular risk factors: "establishing Dert Jour 2010; 31: 2338-2350

\section{Methods}

- 126 newly diagnosed untreated hypertensive patients

- Recruited at the general practitioners' office in the municipality of Aalborg, Denmark

BP:

- 24h ambulatory BP measurements

PWV:

- Applanation tonometry with the Sphygmocor device
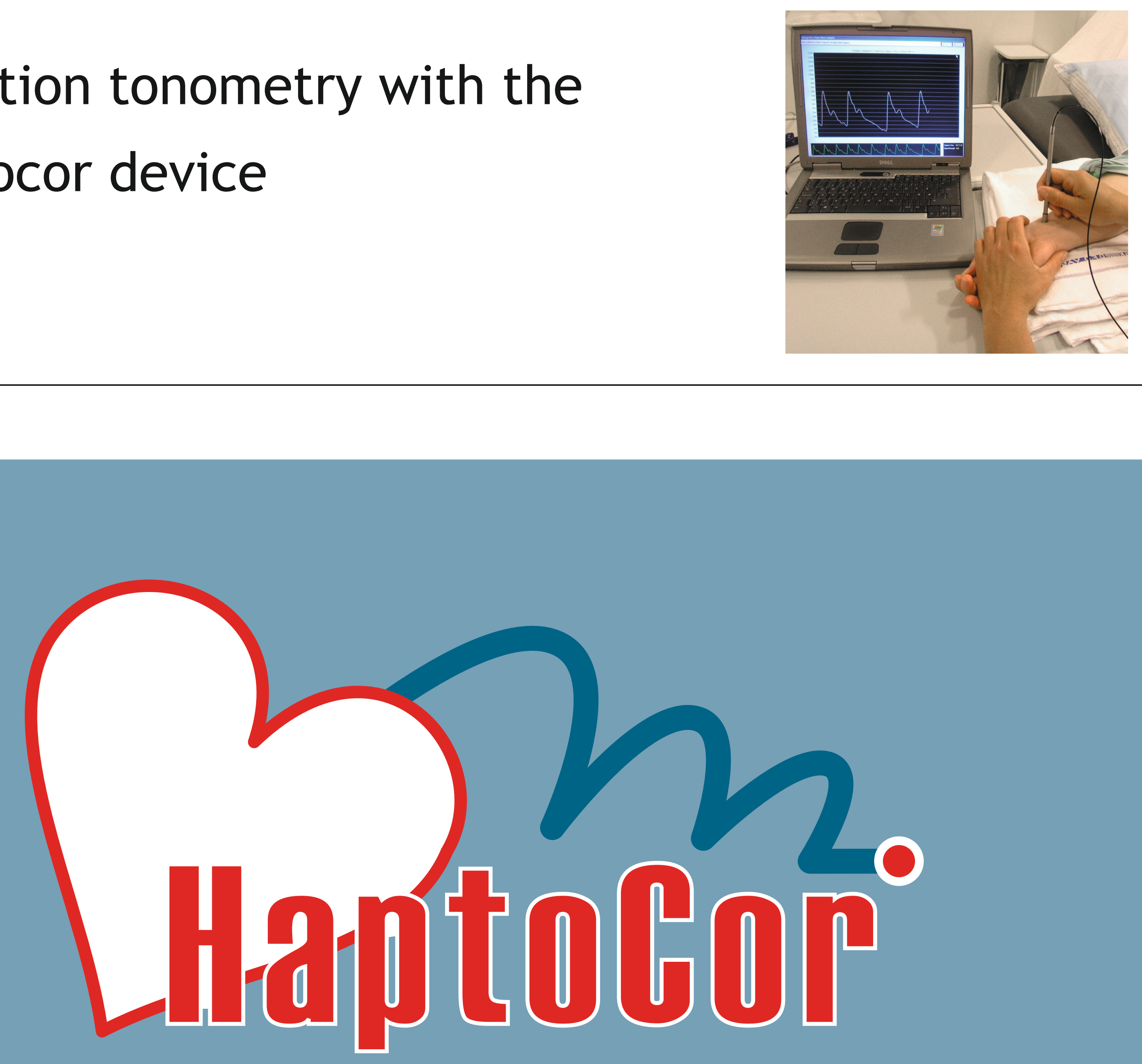

\section{Results}

Table I:

\section{Baseline characteristics}

\begin{tabular}{l|c}
$\mathbf{n}$ & 126 \\
\hline Female $(\mathrm{n})$ & $67(53 \%)$ \\
Age $($ years $)$ & $50[26 ; 73]$ \\
Smoking $(\mathrm{n})$ & $23(18 \%)$ \\
Diabetes mellitus $(\mathrm{n})$ & $3(2 \%)$ \\
Body mass index $\left(\mathrm{kg} / \mathrm{m}^{2}\right)$ & $27[19 ; 41]$ \\
Systolic BP $(\mathrm{mmHg})$ & $145[121 ; 186]$ \\
Diastolic BP $(\mathrm{mmHg})$ & $89[62 ; 122]$ \\
Mean arterial pressure $(\mathrm{mmHg})$ & $107[89 ; 145]$ \\
Heart rate $\left(\mathrm{min}^{-1}\right)$ & $73[48 ; 113]$ \\
PWV $(\mathrm{m} / \mathrm{s})$ & $8.5[5.3 ; 16.8]$
\end{tabular}

Table II: $\quad$ Correlation between PWV and age

$$
\begin{array}{c|c|c}
\multicolumn{1}{c}{\text { B coefficient }} & \mathrm{p} \\
\hline \text { Age } & .09 & <.0001
\end{array}
$$

Figure I Correlation between PWV and MAP

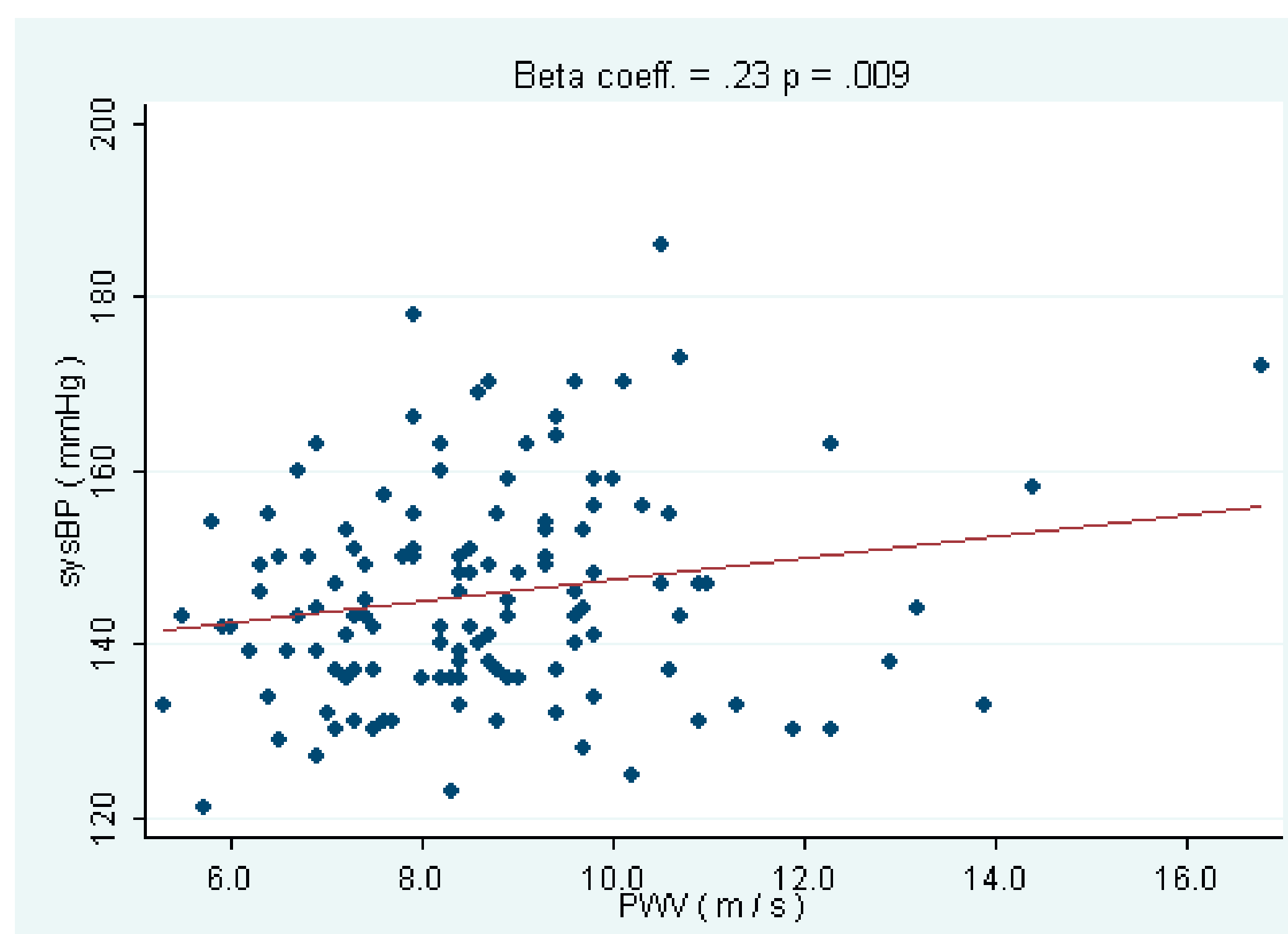

Figure I I Correlation between PWV and sysBP

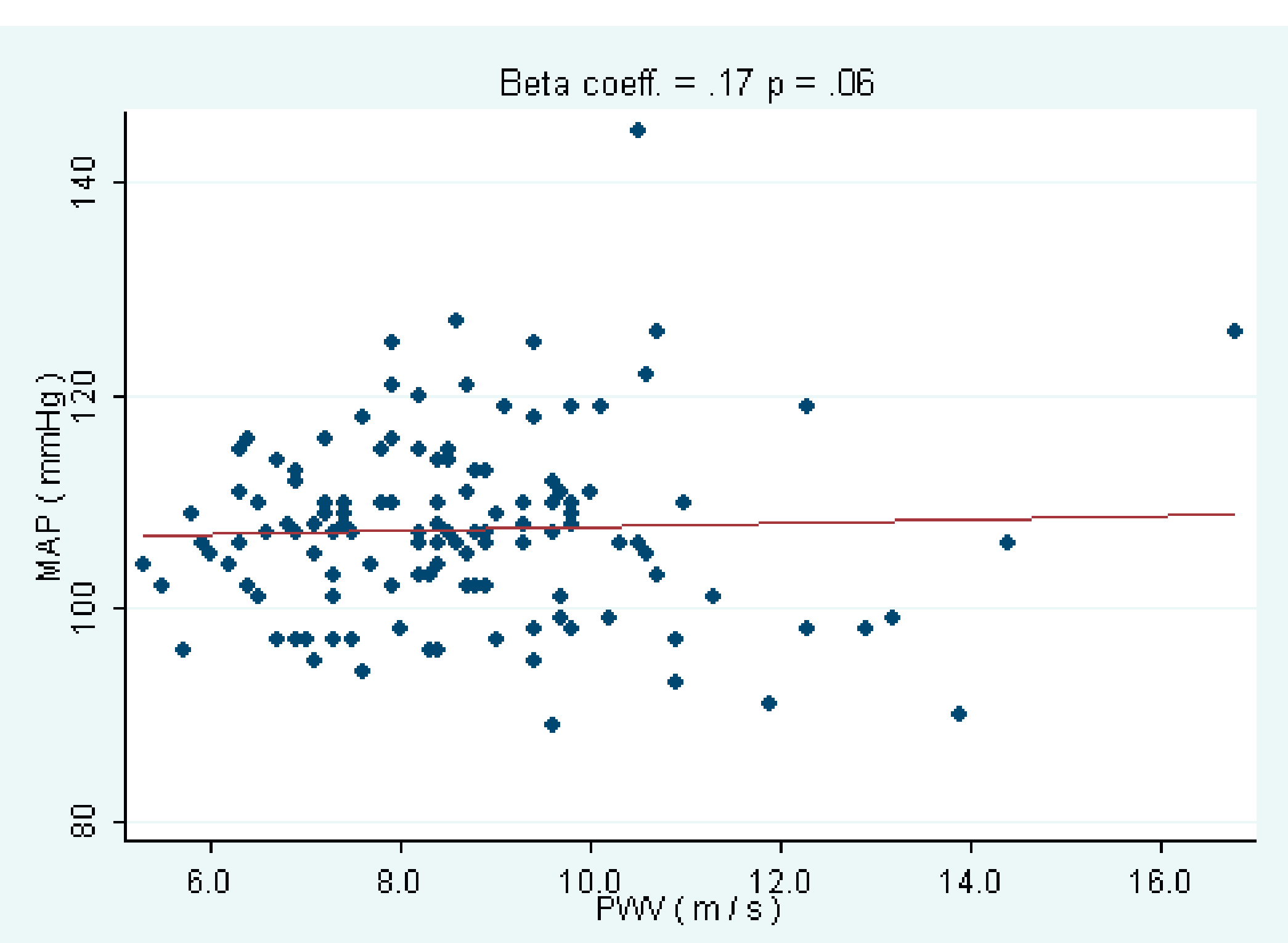

- $\quad$ Steiger's test for equal correlation shows that despite numeric and graphic differences in correlation coefficients the correlations are not statistically different $(p=.2)$

\section{Conclusion}

- PWV measurements must be adjusted for age as well as BP

- Adjusting for sysBP may be superior to adjusting for MAP in newly diagnosed untreated hypertensive patients

- Both numerically and graphically the correlation coefficients are different but can not reach statistically different levels 